\title{
Hybrid Tea-roses under controlled light conditions. \\ 2. Flowering of seedlings as dependent on the level of irradiance
}

D. P. de Vries and L. Smeets

Institute for Horticultural Plant Breeding (IVT), Wageningen, the Netherlands

Key words: Rosa, rose, Hybrid Tea, seedling, irradiance level, mortality, flower bud abortion, winter flowering, genotype-environment interaction

\section{Summary}

Hybrid Tea-rose seedlings were grown in artificial light regimes between 4 and $24 \mathrm{~W} \mathrm{~m}^{-2}$, at a day length of $8 \mathrm{~h}$ and at a temperature of about $21^{\circ} \mathrm{C}$.

Mortality increased with decreasing light intensities. The percentage of flowering seedlings increased and that of aborting ones decreased with irradiance. For the populations studied, no genotype-environment interactions for the percentages of flowering seedlings occurred. A selection procedure for roses with a low light requirement for flowering is considered.

\section{Introduction}

The first paper in this series (de Vries \& Smeets, 1978) reported on the growth and development of Hybrid Tea-rose seedlings in light regimes between 4 and $24 \mathrm{~W} \mathrm{~m}^{-2}$. It was noteworthy that in such populations besides flowering, aborting plants occurred, a phenomenon hitherto unknown or unnoticed in seedlings.

The present study deals with flowering, flower bud abortion and mortality of seedlings as dependent on the level or irradiance. Some preliminary results have shortly been presented in lectures (de Vries, 1974; Sparnaaij et al., 1976; de Vries \& Dubois, 1977).

\section{Material and methods}

The plant material consisted of seedlings arisen from crossing a number of glasshouse varieties of the Hybrid Tea type. Each spring from 1973 to 1976, young seedlings were grown in a growth room of the IVT phytotron. Temperature was about $21{ }^{\circ} \mathrm{C}$, day length 8 hours, and light intensities as presented in Table 1. For further details, see de Vries \& Smeets (1978).

Seedlings of the various populations were equally divided over the levels of irradiance. 


\section{HYBRID TEA-ROSES UNDER CONTROLLED LIGHT CONDITIONS. 2}

Table 1. Years, number of seedlings, irradiances and light sources used.

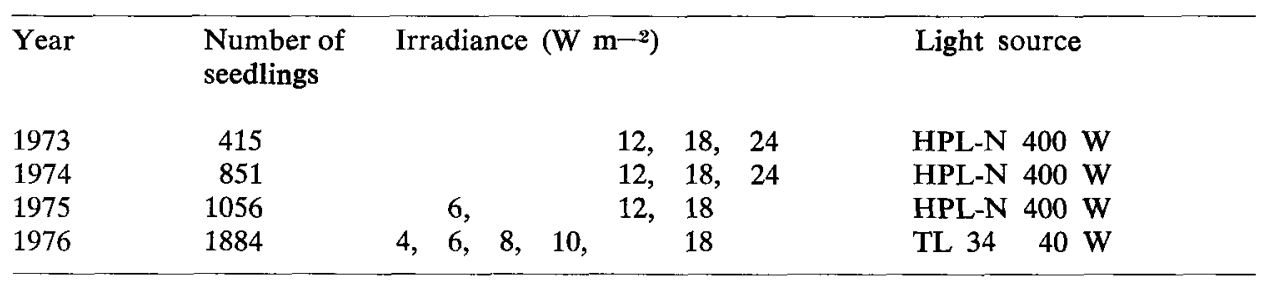

In each experiment observations were made on mortality and the numbers of flowering and aborting plants.

\section{Results}

In each experiment a number of seedlings died. Although as a result of improvements in the cultivation, overall mortality could be reduced considerably (de Vries \& Smeets, 1978), a clear relation between the level of irradiance and mortality could be demonstrated. In 1976, mortality of seedlings decreased markedly with increasing irradiance: $80,46,31,12$ and $7 \%$ mortality at $4,6,8,10$ and $18 \mathrm{~W} \mathrm{~m}^{-2}$, respectively.

In the surviving plants flowering or flower bud abortion was observed. The relation between the level of irradiance and the percentages of seedlings flowering in each of the 4 years is presented in Fig. 1. The percentages of seedlings flowering at the same irradiance increased till 1975 , but no significant differences between 1975 and 1976 occurred. In each year the percentage of flowering seedlings in-

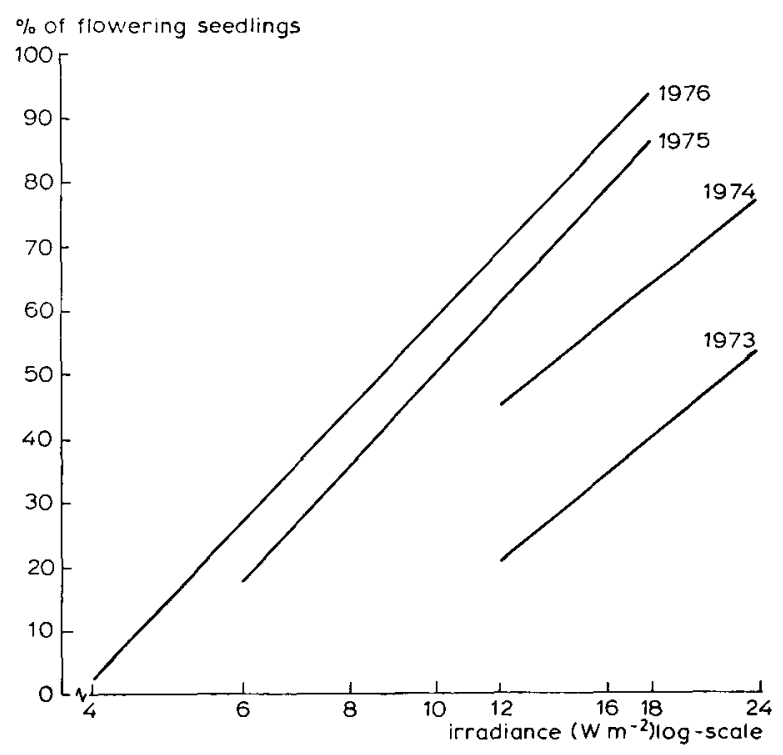

Fig. 1. The relation between irradiance and the percentage of Hybrid Tea-rose seedlings flowering in 4 years (daylength $8 \mathrm{~h}$, temperature $21^{\circ} \mathrm{C}$ ). 


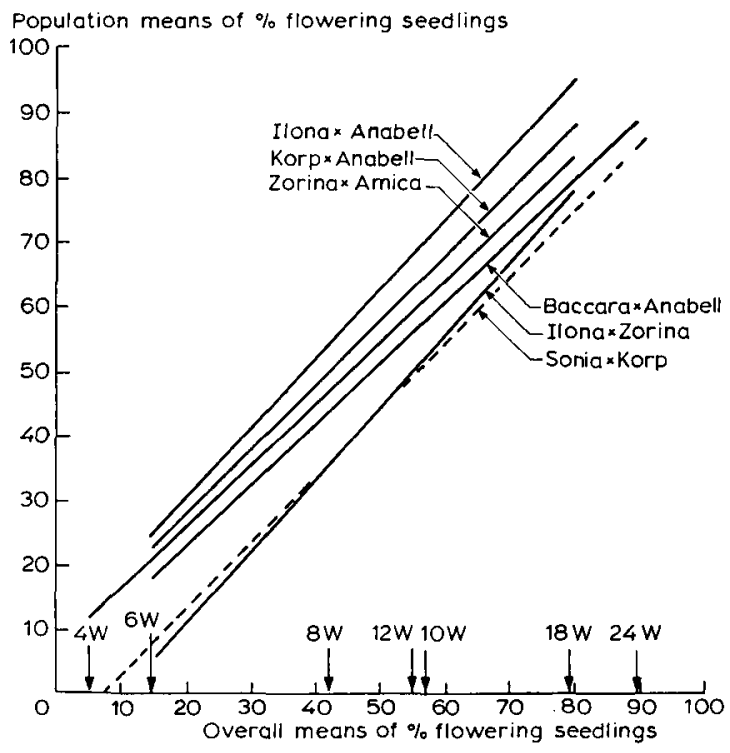

Fig. 2. The relations between the overall mean percentages of flowering seedlings of 6 Hybrid Tearose populations in each of the 7 irradiance regimes (indicated by arrows on the abscissa), and the mean flowering percentages of the individual populations at the same irradiances.

creased (and consequently that of aborting ones decreased) with irradiance. Extrapolation of the regression lines of 1975 and 1976 indicates that all seedlings of these populations would have flowered at about $20 \mathrm{~W} \mathrm{~m}^{-2}$. At $4 \mathrm{~W} \mathrm{~m}^{-2}$, only a low percentage of the few surviving seedlings (Table 2) flowered.

Of the various populations used in the above experiments, only 6 were represented in all 3 years 1974, 1975 and 1976. For this restricted number it was examined whether genotype-environment interactions affected the percentages of flowering plants.

Fig. 2 presents the relation between the overall mean percentages of flowering seedlings of these 6 populations in each of the 7 levels of irradiance, i.e. $4,6,10$, $12,18,24 \mathrm{~W} \mathrm{~m}^{-2}$ and the mean percentages of the flowering seedlings of each individual population at the same irradiances (method after Edwards, 1974). The relations are presented as linear regressions; all correlations between the two parameters were highly significant $(\mathrm{r}>0.90, \mathrm{n}=7)$. The fact that the regression lines run about parallel, demonstrates that no genotype-environment interactions as to flowering occurred. Although the populations differed considerably for the percentages of plants flowering in each environment of irradiance, the populations reacted similarly to an increase in irradiance.

\section{Discussion and conclusions}

Experiments showed that at the lowest level of irradiance used $\left(4 \mathrm{~W} \mathrm{~m}^{-2}\right), 80 \%$ of the seedlings died. Consequently this light intensity is about the minimum required for growth. This agrees fairly well with the statement by Went (1957) that 'most plants cannot grow below 100-200 ft.c', i.e. 4-8 $\mathrm{W} \mathrm{m}^{-2}$, assuming that these data refer to daylight. 
Whether a rose seedling will actually flower or abort its bud, strongly depends on the light intensity. This is a well-established fact in rose varieties, where generally a negative correlation between the light intensity and the incidence of blind shoots occurs (Moe \& Kristoffersen, 1969; Moe, 1971; Zieslin \& Halevy, 1975; KhoshKhui \& George, 1977; de Vries, unpublished).

A similar effect of the light intensity was observed in some bulbous and tuberous ornamentals, such as bulbous iris (Fortanier \& Zevenbergen, 1973), lily (Boontjes et al., 1975) and gladiolus (Shillo \& Halevy, 1976).

As to flowering, large differences in light requirements appeared to exist both between and within rose seedling populations. Flowering even occurred at light intensities that were considerably lower than those prevailing in our latitude in midwinter. This offers unique possibilities for the breeding of roses that are better suited for cultivation in winter. Assuming that no genotype-environment interactions occur, as was demonstrated for the limited number of seedling populations, the differences in flowering between seedling populations need not necessarily be checked at extreme low light intensities. However, individual selection for flowering should be done at such low levels of irradiance that a reasonable proportion of seedlings will grow and flower.

In view of the relatively high mortality at low irradiances, a level for selection of $8 \mathrm{~W} \mathrm{~m}^{-2}$ is recommended.

\section{References}

Boontjes, J., A. J. B. Durieux \& G. A. Kamerbeek, 1975. Progress in the promotion of flowering in lilies by supplementary illumination. Acta Hort. 51: 261-262a.

Edwards, K. J. R., 1974. Effects of temperature on genetic differences in flowering time in Antirrhinum majus. In: The glasshouse environment and objectives in breeding new varieties of ornamental crops. Eucarpia meeting on ornamentals, 1-3 April 1974. John Innes Institute, Norwich, England, p. 32-40.

Fortanier, E. J. \& A. Zevenbergen, 1973. Analysis of the effects of temperature and light after planting on bud blasting in Iris hollandica. Neth. J. agric. Sci. 21: 145-162.

Khosh-Khui, M. \& R. A. T. George, 1976. Responses of glasshouse roses to light conditions. Scientia Hort. 6: 223-235.

Moe, R., 1971. Factors effecting flower bud abortion and malformation in roses. Physiologia Pl. 24: 291-300.

Moe, R. \& T. Kristoffersen, 1969. The effect of temperature and light on growth and flowering of rosa 'Baccara' in greenhouses. Acta Hort. 14: 157-166.

Shillo, R. \& A. H. Halevy, 1976. The effect of various environmental factors on flowering of gladiolus. IV. Interaction of environmental factors - General discussion. Scientia Hort. 4: 157-162.

Sparnaaij, L. D., D. P. de Vries \& J. de Jong, 1976. Problems of selection for adaptation to low light conditions in cut flowers. Acta Hort. 63: 131-139.

Vries, D. P. de, 1974. Rose breeding for poor light conditions. In: The glasshouse environment and objectives in breeding new varieties of ornamental crops. Eucarpia meeting on ornamentals, 1-3 April 1974. John Innes Institute, Norwich, England, p. 67-72.

Vries, D. P. de \& L. A. M. Dubois, 1977. Selectie op winterbloei in rozezaailingen. Vakbl. Bloemisterij 32, 15: 54-55.

Vries, D. P. de \& L. Smeets, 1978. Hybrid Tea-roses under controlled light conditions. I. The effect of the level of irradiance on the growth and development of seedlings. Neth. J. agric. Sci. 26: 119-127. 
Went, F. W., 1957. The experimental control of plant growth. Chronica Botanica Comp., Waltham, USA, p. 11.

Zieslin, N. \& A. H. Halevy, 1975. Flowerbud atrophy in 'Baccara' roses II. The effect of environmental factors. Scientia Hort. 3: 383-391. 